\title{
Influence of transverse ultrasonic vibrations on the efficiency of threaded joint assembly
}

\author{
Aleksandr V. Sukhov ${ }^{1,}{ }^{*}$, Boris A. Cudryashov ${ }^{1}$, Aleksandr A. Nechay ${ }^{1}$, Dmitriy S. Simonov ${ }^{1}$ \\ ${ }^{1}$ Moscow Automobile and Road Construction State Technical University (MADI), 4 Leningradsky \\ prospect, Moscow, Russia
}

\begin{abstract}
The disadvantages arising during assembly of threaded joints are considered. The existing methods of improving the quality of a threaded joint are analyzed and the most promising one is identified - the use of ultrasound at the assembly stage. Dependence of the unscrewing moment on the main technological parameter, which is vibration amplitude is obtained.
\end{abstract}

\section{Introduction}

Bolt-nut joints are the most common type of element joints in mechanical engineering products, while labor costs for their assembly take about $30 \%$ of the total labor costs for assembly [1,2], while about $15 \ldots 20 \%$ of equipment failures during operation are associated with threaded joints, and therefore improving the quality of assembly operations is an urgent task [3].

As a result of the assembly process in a threaded joint, such disadvantages as uneven distribution of the load along the threads, the self-loosening effect, as well as solidification of surfaces when assembling large-diameter joints can occur. To minimize the influence of these shortcomings on the process of threaded joint operation, scientific and design work is being carried out in various directions. To solve the problem of uniform load distribution, it is possible to note the development of various design methods, for example, implementation of a variable average radius of the thread in the nut. This technique enables one to more evenly distribute the load along the threads, however, elements with threads made in this way will significantly exceed the cost of existing bolts and nuts. To prevent self-loosening, various sealants are used, but in this case, the disassembly of the joint is significantly complicated. Various mechanical assembly methods are being improved. A promising method for improving the quality of assembly of threaded joints due to the complex effect on all these disadvantages is the use of ultrasonic vibrations at the stage of joint assembly.

The effectiveness of the use of ultrasound is due to the transformation of the nature of friction from dry to quasi-viscous when vibrations are applied to the joint elements. This reduces the friction coefficient on contact surfaces, which improves the joint quality $[4,5,6]$.

Previous studies show effectiveness of the use of ultrasonic vibrations at the stage of assembling a threaded joint $[7,8,9,10]$. For example, in work [7] it is shown that

*Corresponding author: sukhov-aleksandr96@mail.ru 
superposition of ultrasonic vibrations of longitudinal polarization at high assembly forces is most effective. However, in this work, a thread with a fine pitch was considered, and the twisting couple TC did not exceed $16 \mathrm{Nm}$. This value of TC is not normalized, which does not allow to speak about applicability of the data from [7] for the real process of assembling joints. In [9, 10], ultrasonic wrenches are described, the action of which is based on longitudinal and torsional vibrations. These devices work for both assembly and disassembly of joints, however, they are large enough that they cannot be used in hard-toreach places, for example, when the distance along the assembly axis is limited and openend keys are used for assembly.

It should be noted that, apart from longitudinal and torsional ultrasonic vibrations, other types are practically not considered. In this case, an important factor is position of the threaded joint in the structure. One of the types of vibrations that enables to expand the scope of ultrasound when disassembling and assembling threaded joints are shear vibrations.

\section{Research methodology}

An M10 bolt with a large thread pitch, normal accuracy, $25 \mathrm{~mm}$ long, strength class 5.8 was the element with an external thread. An M10 nut was used as an element with an internal thread.

The tightening torque of the joint was controlled with a torque wrench. Measurement range was $0 \ldots 50 \mathrm{Nm}$, with the scale division of $1 \mathrm{Nm}$. The torque was selected in accordance with the tightening standards for threaded joints according to RD 37.001.131-89 and amounted to $31 \mathrm{Nm}$.

An UZG2-22 ultrasonic generator was used as a source of vibrations. A rod three-halfwave oscillatory system connected to it with a magnetostrictive transducer enables to realize the amplitudes of oscillatory displacements of $2 \ldots 30 \mu \mathrm{m}$. The operating frequency of oscillations is $22 \mathrm{kHz}$. A feedback system was used to monitor and control ultrasonic parameters.

To determine the influence of ultrasonic action on the change in the conditions for assembling a threaded joint, the experiments were carried out according to the scheme shown in Fig. 1.

At the end of the working tool 1 of the ultrasonic oscillatory system, a device for fastening the nut was rigidly fixed, consisting of brackets 2 and 3. A nut was fixed between them, and bolt 4 was screwed into it using wrench 5 . The tightening torque was measured on the scale of dynamometer 6 . The tightening torque was changed by using screw gear 7 . This design is necessary to ensure smooth regulation of the tightening torque of the joint.

Before the start of the experimental study, the bolt was tightened to the standard value on a Mk torque wrench without superimposing oscillations to crush microroughnesses on the contact surfaces of the nut and the bolt. At the first stage of the experiment, the bolt was tightened mechanically using a torque wrench up to $31 \mathrm{Nm}$ without superimposed vibrations, after which ultrasonic vibrations were superimposed on the nut. After the start of the treatment, the decrease in the torque $\Delta \mathrm{M}$ was measured and the connection was tightened up to $31 \mathrm{Nm}$. After tightening, the sonication was stopped, and the unscrewing moment was measured without ultrasound. The vibration amplitude $\xi$ was chosen as the main technological parameter of ultrasonic action. 


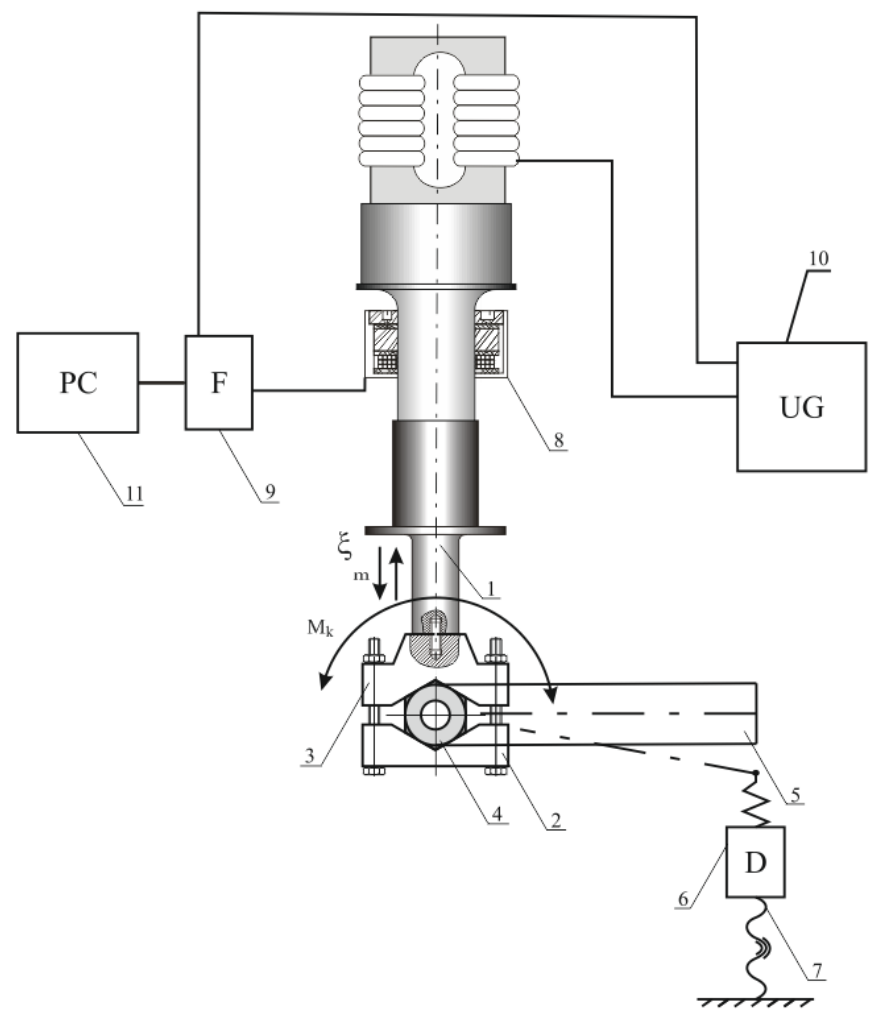

Fig. 1. The scheme of the experiment: 1 - working tool of the ultrasonic vibrating system; 2, 3 brackets; 4 - bolt; 5 - wrench; 6 - dynamometer; 7 - helical gear; 8 - electrodynamic vibrometer; 9 components of the feedback system; 10 - ultrasonic generator; 11 - computer

The amplitude of vibrations of the end face of the working tool was $\xi=1 \ldots 9$ microns. With an increase in the amplitude above $9 \mu \mathrm{m}$, an increased heating of the joint is manifested, which significantly affects the conditions for assembling and disassembling a threaded joint, and therefore, studies at large values of the amplitude have not been carried out.

\section{Experimental research}

The processing of the experimental results was carried out in Statistica program, which enables one to perform regression analysis and obtain information about the reliability of the obtained results. The regression analysis of the obtained data consists of constructing a scatter diagram based on the obtained data, determining the type of fit, the nature of the mathematical model, determining the coefficients of the model and the degree of reliability of the obtained mathematical model $[11,12]$. The polynomial fit was adopted as the most optimal one. Seven types of models were considered from a polynomial of the 1st degree to a polynomial of the 3rd degree. Each model was tested for adequacy using the coefficient of determination $R^{2}$. In addition to the coefficient of determination, Fisher's F-statistic was estimated, which is used to test the hypothesis of zero values of the regression coefficients. The hypothesis is rejected at a low level of significance. The standard error of $\varepsilon$ estimate was also estimated. 
According to the results of the analysis, the most reliable is the 3-degree polynomial model shown in formula 1 :

$$
y=19,50+9,14 A-1,47 A^{2}+0,08 A^{3},
$$

where A - vibration amplitude, $\mu \mathrm{m}$.

In this case, the coefficient of determination $R^{2}=0,81$, for other models the value of $R^{2}$ is less than 0.75 . F-statistic value $=99.571$ at $\mathrm{p}<0.0000$ significance level, i.e. the hypothesis of zero values of the regression coefficients is rejected. The graphically obtained dependence is shown in Figure 2.

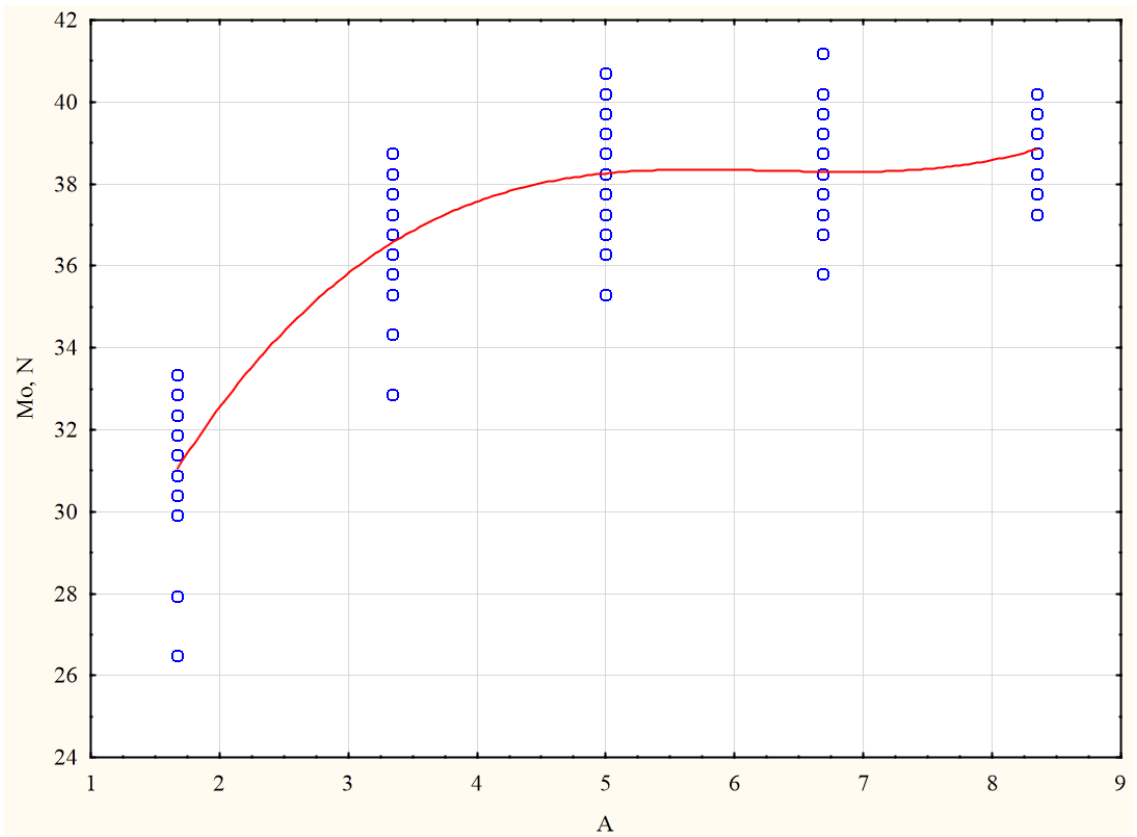

Fig. 2. Dependence of the unscrewing torque on the vibration amplitude

According to the model obtained, the active growth of Mo index proceeds from 2 to 5 $\mu \mathrm{m}$, then the growth slows down and continues up to an amplitude of $9 \mu \mathrm{m}$. The most active growth at low amplitudes is explained by the predominance of the transformation effect of the type of friction from dry to quasi-viscous. After reaching a vibration amplitude of 5 microns, the growth slows down, which is due to the increasing influence of effects that promote self-unrolling. The most effective processing mode for this standard size is processing with vibrations with an amplitude of 5 microns; a further increase in the amplitude does not bring noticeable effect. When processing with an amplitude of $5 \mu \mathrm{m}$, Mo is about $38 \mathrm{~N} * \mathrm{~m}$, which exceeds the value of Mo without ultrasound by $22.6 \%$.

\section{Conclusions}

The main technological parameter when assembling a threaded joint using superposition of shear vibrations on the elements of a threaded joint is vibration amplitude. The most effective processing mode is processing at an amplitude of $5 \mu \mathrm{m}$.

The imposition of shear vibrations on the thread elements during assembly enables the load to be evenly distributed over the thread turns, as well as to increase Mo while 
maintaining the same value of TC. This indicates an increase in the value of the axial force in the joint, which has a positive effect on the assembly quality of the threaded joint.

The use of shear vibrations is proposed for assembly in hard-to-reach places where the use of a face tool is difficult.

\section{References}

1. Berdnikov L.A. Fundamentals of technology for production and repair of cars. Lecture notes for the course/L.A. Berdnikov. - Nizhny Novgorod: Nizhny Novgorod State Technical University named after R.E. Alekseev, 2015. - 339 p.

2. Bobrovitsky V.I., Sidorov V.A. Mechanical equipment: maintenance and repair/V.I. Bobrovitsky, V.A. Sidorov. - Donetsk: Yugo-Vostok, 2011. - 238 p.

3. Lipka V.M. Assessment of influence of the parameters of threaded fasteners on the quality of assembly of power units of cars / V.M. Lipka, Yu.L. Rapatsky // Bulletin of SevNTU. Issue 107: Mechanical engineering and transport: collection of scientific papers; SevNTU - Sevastopol: SevNTU Publishing House, 2010. - pp. 121-127.

4. Nigmetzyanov R.I., Sundukov S.K., Fatyukhin D.S. Ultrasonic assembly of press-fit joints / Russian Engineering Research, 2017, Vol. 37, No. 12, pp. 1044-1047.

5. Prikhodko V.M., Nigmetzyanov R.I., Sundukov S.K., Fatyukhin D.S. Technological possibilities of using ultrasound to improve operational properties of transport engineering products // Science-intensive technologies in mechanical engineering. 2019. - No. 7. - pp. 9-15.

6. Methods for ultrasonic disassembly of part joints. Nigmetzyanov R.I., Prikhodko V.M., Sundukov S.K., Fatyukhin D.S. Repair. Recovery. Modernization. 2017. No. 2. pp. 41-46.

7. Neverov A.N. Disassembly and assembly of threaded joints using ultrasonic longitudinal vibrations // Bulletin of the Moscow Automobile and Road Construction State Technical University (MADI). - 2014. - No. 4 (39). - pp. 54-61.

8. Neverov A.N. Ultrasonic disassembly of threaded connections // Actual directions of scientific research of XXI century: theory and practice. - 2016. - No. 5-4 (25-4). - pp. 75-80.

9. Pat. 188408 Russian Federation, IPC B25B 21/00 (2006.01). Ultrasonic wrench / Krylova I.A., Budnikov Yu.M., Shuvaev V.G.; Federal State Budgetary Educational Institution of Higher Education Samara State Technical University (RU). - No. 2018118644; declared 21.05.2018; publ. 11.04.2019, Bul. No. 11. - 7 p.

10. Shuvaev V.G., Papshev V.A., Shuvaev I.V. Ultrasonic tool for assembly and disassembly of threaded joints // STIN. - 2012. - No. 5. - pp. 37-40.

11. The use of STATISTICA program modules and computational models for solving scientific problems in the field of technical operation of cars: textbook for students, undergraduates and postgraduates of higher educational institutions/A.P. Boldin, V.N. Bogumil - M., Tekhpoligraftsentr, 2016. - 154 p.

12. Fundamentals of scientific research: textbook for students of Institutions of Higher Prof. Education / A.P. Boldin, V.A. Maximov. - M.: Academy Publishing Center, 2012. - $336 \mathrm{p}$. 